\title{
Psychiatric morbidities of elderly psychiatry out-patients in a tertiary-care hospital
}

D. R. Shakya

Associate professor, Department of Psychiatry , B. P. Koirala Institute of Health Sciences, Dharan, Nepal

\begin{abstract}
s
With the rise in life expectancy, the elder population is increasing. Morbidity profiles of elderly people may indicate different needs and priorities. This study aims to sort out referral pattern, attitude about psychiatric referral and morbidity profile among elderly psychiatric outpatients in a general hospital.

A total of 100 consecutive elderly ( $>55$ years) out-patients in psychiatry OPD coming into contact of the investigator and giving informed consent were enrolled. Diagnoses were made according the ICD-10. More (54\%) were female, mainly of age, 55-70 years (79\%). Main ethnicity groups seeking care were Mongol (32\%), Brahmin (25\%), indigenous Terai tribes (14\%) and Newar (11\%). People from cities and semi-urban settings predominated the study. Referrals made most commonly by the departments were medicine, family medicine, surgery and ENT. More than a fourth (28\%) were dissatisfied and questioned about the referral to psychiatric service. Greater proportions (71\%) were comfortable and happy about psychiatry referral. Mood related and physical complaints each were presenting complaints in about half of subjects. Major psychiatric diagnoses were mood affective, anxiety, substance use and organic psychiatric disorders. Great majority had physical co-morbidity. Common mental disorders among elderly psychiatry out-patients were mood affective, anxiety and substance use disorders. A significant number of elderly psychiatry out patients had physical comorbidity.
\end{abstract}

Key words: Attitude to psychiatric consultation, geriatric, Nepal, out-patient, psychiatric morbidity.

\section{Introduction}

This era is witnessing an unprecedented faster population ageing, ${ }^{1}$ and so is Nepal. ${ }^{2}$ With this, there has been a great concern about particular problems, needs and priorities of senior citizens. ${ }^{1,3}$ Along with changes affecting body, mind and social relationship; elder people may have many health

Correspondence: D.R. Shakya

E-mail: drdhanashakya@yahoo.com problems. Unfortunately, they receive inadequate attention and mental illness receives even less attention. Many psychiatrically ill elderly people hesitate to seek help from mental health professionals and prefer other health professionals because of various reasons. Their psychiatric morbidity profile may indicate different pattern and needs. ${ }^{4}$ 
Information about their morbidity profiles will help uplift awareness among medical professionals and public about the problems and facilitate appropriate management at all levels. There is, however a lack of data regarding psychiatry morbidity profile among elder psychiatry out-patients in Nepal.

This study was conducted to sort out psychiatric referral patterns, attitude towards psychiatric referral and morbidity profiles in elder out-patients.

\section{Materials and methods}

This is a hospital based descriptive cross sectional study with convenient sampling. The subjects for this study consisted of 100 consecutive patients of age $>55$ who consulted with the investigator psychiatrist in psychiatry out-patient department (OPD) of B. P. Koirala Institute of health Sciences (BPKIHS), a tertiary-care hospital in eastern Nepal, since August 2008. This study was approved by and presented in the 'Scientific program of the institute'. After a brief explanation about the study to the subjects and significant care-giver, an informed consent was collected. The information was kept confidential.

The socio-demographic profile and information about the illness (source of referral, co morbid conditions, and psychiatric diagnosis) were recorded on the particular sheet. Detailed psychiatric work-up was done in all subjects. Referrals and investigations were advised as per need. The final psychiatric diagnosis was made according to the 'International classification of disease and infirmity, $10^{\text {th }}$ edition' (ICD-10) criteria. ${ }^{5}$ Physical diagnoses were as per the departments who referred the particular cases. Those diagnoses were later arranged as per the ICD10.

The view of patients and or caretakers regarding psychiatric referral and the steps of help seeking to the present service were explored during the consultation. The overall responses about their view regarding the referral were sorted out into 5 categories- dissatisfied, questioning the referral, comfortable, happy and satisfied and no response. Data were entered into a computer and analyzed using 'Statistical Package for Social Science' (SPSS) - software.

\section{Results}

A maximum number of cases were from the age groups: 55- 60 years (47\%), 61- 65 (16\%) and 66$70(16 \%)$. The mean age of the cases was 65 years, with the age range of 55- 86 years. Females were 54\%. (Table-1)

The main caste-ethnic groups seeking help were: Mongols (32\%), Brahmins (25\%), indigenous Terai tribes (14\%) and Newars (11\%). The cases were mainly from semi-urban and city areas ( $40 \%$ each). We had 5\% Indian geriatric patients in this study. (Table- 2)

Two thirds of the cases $(67 \%)$ were referred by different departments of the same institute, mainly medicine $(30 \%)$, family medicine and emergency (14\%), surgery (8\%) and ENT (7\%). One case was 
D. R. Shakya, Psychiatric morbidities of elderly psychiatry

referred by a traditional healer, $7 \%$ by private practitioners and $25 \%$ came on the advice of nonhealers like their family, relatives, friends, neighbours, other patients or even media and self. (Table- 3)

Most of the cases had visited other sources of health service- 3 in $32 \%$ and 4 in $27 \%$ cases (mean number of different treatment modalities being 4.18, the one most common being some sort of home remedies) before coming to the service. (Table- 4 )

A few cases $(2 \%)$ were utterly dissatisfied, many (26\%) questioned about the psychiatric referral, greater proportions (57\%) were comfortable, 14\% were happy and satisfied regarding referral, and 1\% did not answer. (Figure- 1)

Common presenting complaints were mood, physical/ somatic and anxiety symptoms. A great number of cases had many other complaints. Two percents had suicidal behaviors. (Figure- 2).

Major psychiatric diagnoses were mood affective (in 46\%), anxiety disorders (in 22\%), substance use disorders (in 19\%), organic and symptomatic psychiatric disorders (in 12\%) and somatoform disorders (in 10\%). (Table 5)

A great majority of them (89\%) had different physical diseases along with some psychiatric problems, mainly cardiovascular (in 40\%), neurological (in 19\%) and gastrointestinal (in 17\%). (Table 6)
TABLES- In the order they appear

Table 1: Age and Gender distribution-

\begin{tabular}{ccc}
\hline S. No. & $\begin{array}{c}\text { Age Group } \\
\text { (in years) }\end{array}$ & $\begin{array}{c}\text { No. of } \\
\text { Subjects/ } \%\end{array}$ \\
\hline 1 & $55-60$ & 47 \\
2 & $61-65$ & 16 \\
3 & $66-70$ & 16 \\
4 & $71-75$ & 5 \\
5 & $76-80$ & 9 \\
6 & $>81$ & 47 \\
\hline & Gender & \\
\hline 1 & Male & 46 \\
2 & Female & 54 \\
\hline & Total & 100 \\
\hline
\end{tabular}

Table 2: Ethnicity-caste and Place of domicilesEthnicity-caste Frequency/ Percentage

Brahmins 25

Chhetri 8

Mongolians 32

Newar 11

Terai tribe-castes 14

Dalit/disadvantaged 5

Indians

5

\begin{tabular}{lc}
\hline Place of domiciles & Number/\% \\
\hline Urban & 40 \\
Semi-urban & 40 \\
Rural & 15 \\
India & 5 \\
\hline
\end{tabular}


Table 3: Referral Sources- (in \% of total)-

\begin{tabular}{llc}
\hline S. No. & Source of Referral & No./\% \\
\hline 1 & Internal medicine & 30 \\
2 & Family medicine \& emergency & 14 \\
3 & Surgery & 8 \\
4 & ENT & 7 \\
5 & Orthopedics & 3 \\
6 & Ophthalmology & 3 \\
7 & Dermatology & 2 \\
8 & Private practitioner & 7 \\
9 & Traditional healers & 1 \\
10 & Others (self, friend, media, & \\
\hline
\end{tabular}

Table 4: Number of other Help seeking steps before reaching this psychiatry OPD

\begin{tabular}{lc}
\hline $\begin{array}{l}\text { No. of steps when in Psych } \\
\text { OPD of BPKIHS }\end{array}$ & $\begin{array}{c}\text { Frequency } \\
/ \%\end{array}$ \\
\hline $3^{\text {rd }}$ step (including BPKIHS) & 9 \\
$3^{\text {rd }}$ step & 19 \\
$4^{\text {th }}$ step & 32 \\
$5^{\text {th }}$ step & 27 \\
$\leq 6^{\text {th }}$ step & 13 \\
\hline
\end{tabular}

Table 5: ICD 10 Psychiatric Diagnosis*-

\begin{tabular}{|c|c|c|}
\hline ICD code & Psychiatric diagnosis & No./ $\%$ \\
\hline
\end{tabular}

Dementia 6

Delirium 2

Seizure related 4

F 10- 19 Substance use 19

Alcohol related 14

F 20- 29 Schizophrenia, schizotypal \& delusional 6

F 30- 39 Mood (affective) 46

F 30-34 Manic episode, Bipolar

F 38,39 affective 7

Depressive illness 39

F 40- 45 Phobic, other anxiety and

Obsessive compulsive 22

Stress related/ adjustment 3

Somatoform 10

F 50- 59 Associated with physiological/ physical factors 9

X 60- X 84 Deliberate self harm/ suicide attempts 2

Absent/ deferred 5 
D. R. Shakya, Psychiatric morbidities of elderly psychiatry

Table 6: Physical Diseases*-

\begin{tabular}{|c|c|c|}
\hline ICD code & Physical diseases & No./ \% \\
\hline A00- B99 & Infection/ infestation & 6 \\
\hline C00-D48 & Neoplasm/ Cancers & 3 \\
\hline \multirow[t]{2}{*}{ E00-E90 } & \multicolumn{2}{|l|}{ Endocrine, nutritrional \& } \\
\hline & Metabolic & 3 \\
\hline G00-G99 & CNS- Neurological & 19 \\
\hline H00-H59 & Eye & 7 \\
\hline H60-95 & ENT & 3 \\
\hline I00-I99 & Circulatory/ Cardio-vascular & 40 \\
\hline J00-J99 & Respiratory & 8 \\
\hline K00-K93 & Digestive/ Gastro-intestinal & 17 \\
\hline L00-L99 & Skin diseases & 3 \\
\hline \multirow[t]{2}{*}{ M00-M99 } & \multicolumn{2}{|l|}{ Musculoskeletal \& connective/ } \\
\hline & Orthopedics & 7 \\
\hline N00-N99, & Genito-urinary and obstetric/ & \\
\hline O00-O99 & Gynecological & 4 \\
\hline \multirow[t]{5}{*}{ X60- X84 } & Intetional/ Deliberate self & \\
\hline & harm, suicide attempts & 2 \\
\hline & Surgical & 6 \\
\hline & Dental & 1 \\
\hline & Absent & 11 \\
\hline
\end{tabular}

* Multiple response category - One respondent may have one or more responses

\section{Attitude about the referral}

(No. of subjects/\%)

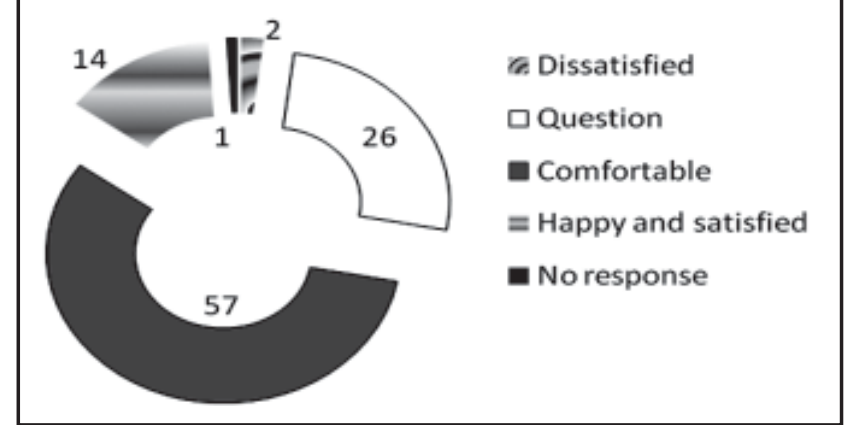

Figure 1: Perception/ attitude among the subjects about Psychiatric referral-

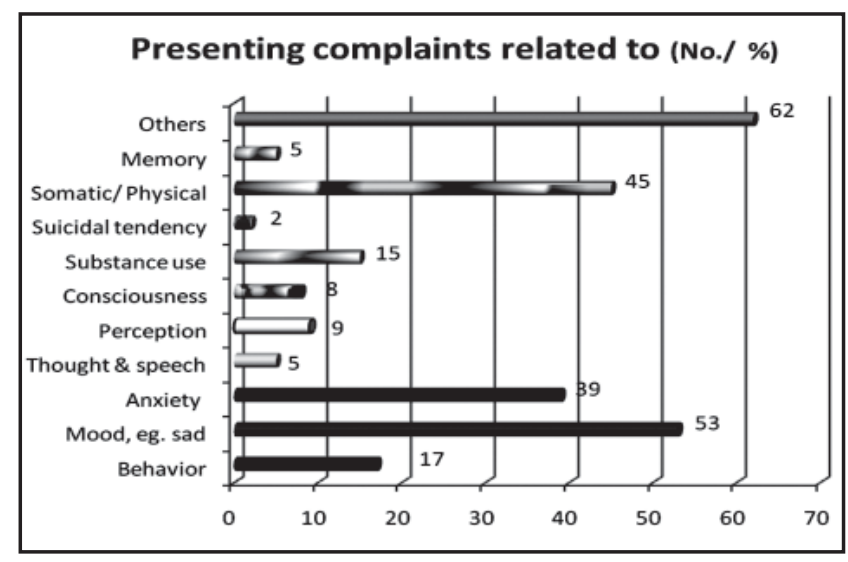

Figure 2: Presenting Complaints*_

\section{Discussion}

Nepal is yet to start a formal geriatric psychiatric service. There is an extreme scarcity of mental health resources for this service. ${ }^{6}$ Major teaching institutes such as TU teaching hospital, Kathmandu and B P Koirala Institute of Health Sciences, Dharan provide mental health services, also for 
Journal of College of Medical Sciences-Nepal, 2011, Vol-7, No-4

elderly patients. With the current trend of establishment of medical institutes, both in and outside the capital city, ${ }^{7}$ the psychiatric service to senior citizens is also beginning to reach different parts of Nepal through general psychiatrists. Psychiatric service of a general hospital has extra advantages of: easier access, less stigma and visible acceptance to medical field. ${ }^{8}$ In current Nepal, there is a lack of data, particularly from eastern Nepal, i.e. BPKIHS regarding psychiatric morbidity among elderly patients. In the pretext of the dearth of data, current study was carried out here with the optimism that it would pave a way to further studies.

This institute based study was carried out among 100 consecutive psychiatry-OPD patients of age $>55$ years who visited the department for the first time and came into the contact of the investigatingteam during the study period. Nepalese population is in the phase of ageing and current life expectancy is 65.8 years. ${ }^{9}$ In the pretext of growing age, we had chosen 55 years and above as an inclusion criteria. ${ }^{10}$ Age distribution of current study noticeably revealed that we had more patients of younger ages, i.e. 55 to 70 years (79\%) though the age range was 55- 84 completed years. And, also many old people of elder age groups might not have been brought to a medical attention. Hence, it indicated the need for raising awareness about psychological problems of this age group.

The ethnicity distribution was more or less similar to the population distribution of this region. The representation of disadvantaged or dalit groups however is comparatively less. It may possibly be because of their backwardness in awareness, financial status or even shorter life span. It warrants further exploration. The subjects were mainly from urban and semi-urban settings; relatively less from rural areas. This finding indicates some possibilities which need further studies: many ill elder people from rural setting might have not come into medical attention, possibly elder people were less there or they were relatively healthier than urban counterpart. Equal representation of semi-urban as urban counterpart seen in this study and the fact that this institute is situated in a city surrounded by villages, indirectly support the first possibility. As in other similar profile studies from the same institute, ${ }^{8,11,12}$ there were many Indian elder patients $(5 \%)$ in this study: indicating bilateral relationship between Nepal and India.

The pathway of help seeking and the referral source immediately preceding the psychiatric out-patient service in this study revealed that majority of the cases visited many other sources (mean number of different treatment modalities being 4.18, some sort of home remedies being the most common) before coming to this service. This might result in loss in terms of: time, resources, suffering, treatment delay and complications. Similar pattern of help seeking has been reported in other studies from this part of the country. ${ }^{7,8,11-13}$

Two thirds of the total cases were referred to a psychiatric service by other departments of the institute (main being internal medicine, family medicine and emergency, surgery and ENT), 7\% by private practitioners and $26 \%$ by other sources, e.g. friends, relatives, neighbors, other patients, 
D. R. Shakya, Psychiatric morbidities of elderly psychiatry..

traditional healers, self and even the media. Many people (28\%) were either not happy or questioning about the psychiatric referral in this study. Upon the question about their perception regarding the referral, one subject declined from answering. This finding and the small number of people directly seeking psychiatric service (without being referred by other medical specialties) clearly point out the need for intensive public awareness measures. The referral from local practitioners and other departments was however a welcome sign. Gradual improvement is expected in the attitude among people about psychiatric service with the positive view and explanation of non-psychiatrist medical professionals about psychiatric referral and constant display of its advantage.

The preponderance of mood, physical and somatic, anxiety, behavioral symptoms, substance use and other complaints were nearly keeping with the diagnostic profiles. The relatively greater presentation with mood, substance use, abnormal behavior, altered consciousness and perceptual abnormalities in this study than in similar study among adult referred-OPD cases in the same institute $^{8}$ is again consistent with diagnostic profile.

The diagnostic profile replicated the predominance of mood affective, mainly depressive illness, followed by phobic and anxiety, substance mainly alcohol use disorders, organic and symptomatic mental disorders (e.g. delirium, dementia) and somatoform disorders. The mood, anxiety and organic psychiatric disorder stand out prominent as in other studies from other parts. ${ }^{3,4}$ Substance use disorder clearly appears to be out-standing here which replicates the high community prevalence of this problem in this part of the country. ${ }^{14}$ Some elder patients $(2 \%)$ were brought to the clinic primarily for suicidal tendencies. This figure is comparatively less than in a study of referred OPD profile and psychiatric emergency studies of the same institute. ${ }^{8,15}$

In $89 \%$ of the elder out-patients, physical diseases were co-morbid with psychiatric disorders, hence stressing the need of closer integration of psychiatric services with other specialties. This is consistent with other studies of this age group in other parts. ${ }^{3,4}$

\section{Conclusion}

Majority of elder out-patients visit other sources of help-seeking before coming to a psychiatric service for different psychological problems. Mood, physical and somatic symptoms, anxiety, substance use, abnormal behaviors were common presenting complaints among elder psychiatric out-patients. Common diagnoses among these elder psychiatryOPD-cases were mood affective, anxiety, substance use, organic mental and behavioral and somatoform disorders. A great majority had one or other physical comorbidities.

\section{Recommendation}

Inter-departmental collaboration and multidisciplinary approach is necessary for the holistic management of geriatric psychiatric problems. 


\section{References}

1. UN Department of Economic and Social Affairs Population Division. World Population Ageing: 19502050. Available at: http://www.un.org/esa/population/ publications/worldageing 19502050/. Accessed in December 11, 2010.

2. Central Bureau of Statistics (CBS), Government of Nepal. Population profile of Nepal. Available at: http:/ / w w w . c bs.gov.n p/Population/ Population\%20Profile\%20of\%20Nepal.pdf. Accessed in December 11, 2010.

3. V.B. Singh, K.C. Nayak, D.K. Kataria et al. Psychiatric Co-morbidities in Patients Attending Geriatric Clinic at a Tertiary Care Hospital. Journal of the Indian Academy of Geriatrics 2005;2: 65-9.

4. B.V.B. Khardia, K.S. Kumar. Geriatric Psychiatric Morbidity in North-Western Part of India. Paper presented in 'the IPA European Regional Meeting (14 April 2003) of IPA'. (Abstract) available at: http:// asm.confex.com/ipa/2003_Geneva/techprogram/ session_1658.htm. Accessed in December 12, 2010.

5. World Health Organization. The ICD-10 Classification of Mental and Behavioral Disorders: Clinical Descriptions and Diagnostic Guidelines. WHO. Geneva. 1992.

6. P.M. Shangwa, A. Jha. Nepal: trying to reach out to the community. International Psychiatry 2008;5(2): 36-8.

7. D.R. Shakya. Psychiatric Emergencies in Nepal. Developing Mental Health, UK. International Journal for Mental Health Care UK 2008; 6(8):5-7.
8. D.R. Shakya, A.K. Pandey, P.M. Shyangwa, Psychiatric morbidity profiles of referred Psychiatry OPD patients in a general hospital. Indian Medical Journal 2009; 103(12):407- 11.

9. CIA World Factbook. Nepal Demographics profile. Available at: http://www.indexmundi.com/nepal/ demographics_profile.html. Accessed at December $5,2010$.

10. World Health Organization. Definition of an older or elderly person. Proposed working definition of an older person in Africa for the MDS project. Available at: www.who.int/healthinfo/survey/ageingd. Accessed at December 11, 2010.

11. D.R. Shakya. Psychiatric morbidity profiles of Child and adolescent Psychiatry out-patients in a tertiarycare hospital. J Nepal paediatr soc 2010;30(2): 7984.

12. D.R. Shakya. Clinico-demographic profiles in Obsessive compulsive disorders. J Nepal Med Assoc. 2010; 49(178): 133-8.

13. D.R. Shakya, P.M. Shyangwa, B. Sen. Help seeking behaviour in Alcohol dependence syndrome in BPKIHS. Paper presented in the $2^{\text {nd }}$ SAARC Psychiatric Federation Conference, Kathmandu, November, 2006.

14. H.P. Jhingan, A. Sharma, S. Koirala et al. Prevalence of alcohol dependence in a town in Nepal as assessed by CAGE questionnaire. Addiction 1998; 339-43.

15. D.R. Shakya, Shyangwa, R. Shakya. Psychiatric Emergencies in a tertiary care Hospital. J Nepal Med Assoc. 2008; 169(47): 29-34. 